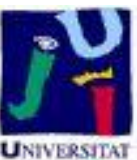

Título artículo / Títol article: Geospatial information infrastructures to address spatial needs in health:

Collaboration, challenges and opportunities

Autores / Autors Carlos Granell,

Óscar Belmonte Fernández,

Laura Díaz

Revista:

Future Generation Computer Systems

Versión / Versió:

Cita bibliográfica / Cita bibliogràfica (ISO 690):
Versió post-print

GRANELL, Carlos; FERNÁNDEZ, Óscar

Belmonte; DÍAZ, Laura. Geospatial information infrastructures to address spatial needs in health: Collaboration, challenges and opportunities. Future Generation Computer Systems, 2014, vol. 31, p. 213-222.

url Repositori UJI: ～～http://hdl.handle.net/10234/89109 


\title{
Geospatial information infrastructures to address spatial needs in health: collaboration, challenges and opportunities
}

Carlos Granell (European Commission, Joint Research Centre, Ispra, Italy)

Óscar Belmonte Fernández (Institute of New Imaging Technologies, Universitat Jaume I, Castellón, Spain)

Laura Díaz (Institute of New Imaging Technologies, Universitat Jaume I, Castellón, Spain)

\begin{abstract}
:
Most health-related issues such as public health outbreaks and epidemiological threats are better understood from a spatial-temporal perspective and, clearly demand related geospatial data sets and services so that decision makers may jointly make informed decisions and coordinate response plans. Although current health applications support a kind of geospatial features, these are still disconnected from the wide range of geospatial services and datasets that geospatial information infrastructures may bring into health. In this paper we are questioning the hypothesis whether geospatial information infrastructures, in terms of standards-based geospatial services, technologies, and data models as operational assets already in place, can be exploited by health applications for which the geospatial dimension is of great importance. This may be certainly addressed by defining better collaboration strategies to uncover and promote geospatial assets to health community. We discuss the value of collaboration, as well as the opportunities that geographic information infrastructures offer to address geospatial challenges in health applications.
\end{abstract}

Keywords: Information Infrastructures for Collaboration; Geospatial Information Infrastructures (Glls); Geospatial Services; Health applications; Collaboration between health and geospatial services

This paper can be cited as:

C. Granell, O. Belmonte, L. Díaz. Geospatial information infrastructures to address spatial needs in health: collaboration, challenges and opportunities. Future Generation Computer Systems, 31: 213-222, 2014, ISSN 0167-739X.

http://dx.doi.org/10.1016/j.future.2013.04.002 


\section{Introduction}

Current concerns in our society are related to human health and environmental issues that demand interdisciplinary and collaborative approaches to analyse complex patterns and correlations. The notion of collaboration is an inherent characteristic in interdisciplinary research activities [1]. For instance, research teams share datasets, documentation, experiments, and jointly perform daily research tasks with peers through distributed information infrastructures [2].Collaboration also becomes critical in health situations such as disease outbreaks in which involved stakeholders (e.g., healthcare institutions, first responders) must jointly coordinate actions, global strategies and emergency plans in response to this issue. These plans stemmed from the integration, sharing and access to needed datasets and services from diverse information infrastructures, whenever these infrastructures collaborate with each other [3].

Geospatial information infrastructures (Glls) make services available for discovery, accessing, processing, visualization, and managing spatio-temporal datasets [4]. Glls can be seen as a network of infrastructure nodes at different scales (e.g., local, regional, national) [5]. In essence, collaboration between these nodes enables the creation of different applications such as geospatial analysis, decision-making, and policy analysis applications, which use of geospatial datasets and services deployed across distributed nodes in Glls.

Collaboration between health and Glls is then central in this paper. Rather than reinventing the wheel, we are questioning the hypothesis whether Glls, together with specialized geospatial services, can be (re)used to address geospatial needs in health applications. The latter does not mean that all of the health applications have spatial requirements to be covered by Glls. Reports on health statistics likely contain no geospatial services. Conversely, infectious disease outbreaks clearly require geospatial datasets and analysis such as the generation of disease dispersion maps in a city for enhancing informed decision-making processes. Furthermore, we focus on the concept of collaboration between health and geographical information infrastructures by identifying geospatial needs in health that may be addressed by existing geospatial services and related specifications and standards.

The rest of the paper is organized as follows. In Section 2 we point out the key role of Glls might have to support health scenarios that explicitly demand geospatial functionalities, highlighting the need for collaboration between thematic information infrastructures to solve cross-cutting application scenarios. In Section 3 we indicate areas of collaboration between health and Glls through the identification of challenges in health applications that may be supplied by specialized geospatial services. Finally, we present concluding remarks in Section 4.

\section{The need for collaboration}

Collaboration is crucial to foster capacity building among different kinds of stakeholders such as research organizations, public health departments, decision makers, social media and citizens in general. In such a context, information infrastructures -in terms of institutional and social 
arrangements as well as technologies, specifications and protocols- are baseline to allow sharing resources, data and services as well as to enable coordination of actions and decisions between user, stakeholders and data providers.

Health Information Infrastructures (HIIs) and Glls share many commonalities as well as issues and needs. For instance, health applications involve heterogeneous and diverse types of organizations, such as health agencies at different levels (local, regional and national), hospitals networks, in-situ or mobile health units (e.g., ambulances), first responders, and even citizens. All of them act in a synchronous basis to provide for example rapid responses to health outbreaks. However, it is widely recognized that each health agency and institution may have distinct data models, service interfaces, and communication protocols, which are barriers towards an effective collaboration between participating agencies [6]. In Glls, national and local mapping agencies also work collaboratively to collect data in distinct geographical areas to avoid duplication in data production [7]. For instance, local mapping agencies have better knowledge of their coverage area than the corresponding national mapping agencies. Glls follow the simple principle of locality: locals living in a given area have more geographical knowledge than non-local people. Furthermore, local mapping agencies and providers are in charge of collecting data once, but allowing sharing through suitable standards-based geospatial services on top of Glls to other interested users.

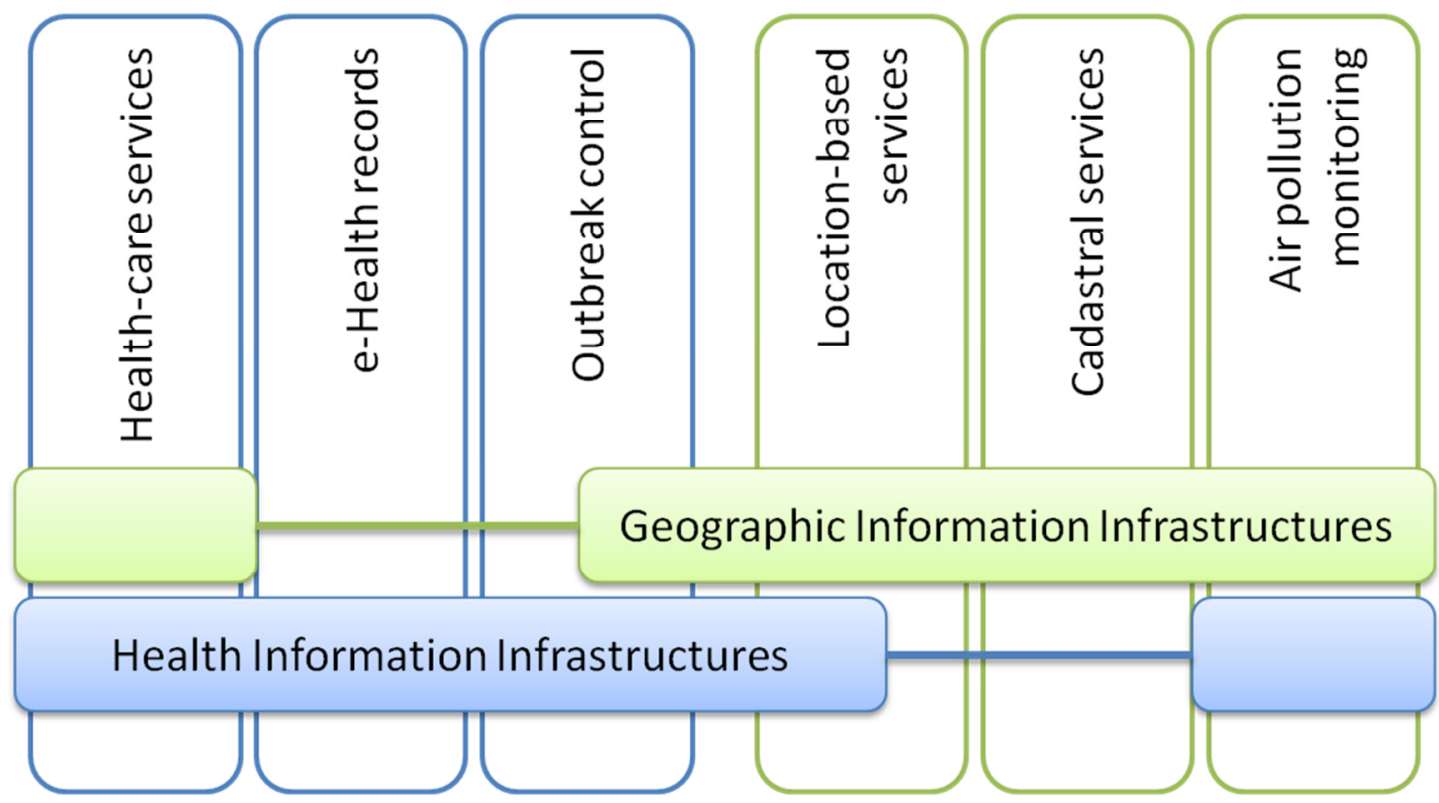

Figure 1. Geographic and health information infrastructures collaborate to address cross-cutting issues. Some application scenarios may rely mainly on one thematic information infrastructure. Others, though, like outbreak control additionally require geospatial capabilities that can be supplied by specialized geospatial services from geographic information infrastructures.

Decision making processes in health require a multi-disciplinary and integrated approach [8]. Other disciplines such as environmental sciences and policy analysis also involve multidisciplinary research groups and a wide range of stakeholders to find a solution to a given environmental problem [9]. Indeed, current environmental problems can be addressed only from 
a collaborative and multidisciplinary perspective, since small and independent research groups are not able to address global problems [10]. Otherwise, ambiguous or partial results may lead to wrong decisions and bad policies, which in some critical domains like health are unacceptable. Monitoring epidemiological outbreaks, for example, not only requires epidemiological datasets from data providers (e.g. public health agencies) but also demand census and statistics data, city district names, geocoding services that altogether help decision makers in collecting trusted information to take proper actions (Figure 1). In this paper the term collaboration refers to the feasibility to (re-)use specialized geospatial services from Glls to address health issues such as diseases outbreak control for which the spatial dimension is of great importance [11].

Apart from the above motivation - sharing efficiently data and services and promoting collaboration between information infrastructures to address global health issues-, other authors have identified additional reasons for promoting collaboration between health and geographic information infrastructures. Kamel Boulos [12] already indicated the potential of specific geospatial tools to address multiple health situations such as the analysis of disease patterns and disease rates [13]. Thompson et al. [6] recently suggested that some tasks in health resource management (e.g., where to place the next local health-care services) demand geospatial information such as geo-referenced demographic and population base layers, but most importantly geospatial analysis and visualization capabilities to enhance informed decision-making processes. Furthermore, specific demands require specific capabilities supplied by the corresponding infrastructure, i.e., geospatial data and services may be exported to other infrastructures to meet specialized geospatial requirements [14].

The above list of geospatial needs does not intend to be exhaustive but reflects the importance of the geospatial dimension in health applications. Glls have been proposed to address the geospatial needs of practical interaction and interoperability between data, integration technologies, policies, institutional arrangements, and people, to help users with heterogeneous needs in problem solving tasks. Interoperability in Glls is accomplished in part because the geospatial community, under the auspices of the Open Geospatial Consortium (OGC) and other standardization bodies, such as the International Organization for Standardization (ISO), have agreed in a set of service interfaces and data encodings for dealing with geospatial data and resources. Figure 2 illustrates a simplified architecture for Glls where geospatial resources are accessed and shared via standards-based, specialized OGC service interfaces. The standardization of services interfaces enable easy sharing, integration and interoperable access to a wealth of geospatial resources. Examples are Web Map Service (WMS) [15], Web Feature Service (WFS) [16] (also ISO/DIS 19142, Geographic information - Web Feature service), Web Coverage Service (WCS) [17], Sensor Observation Service (SOS) [18], Catalogue Service for Web (CSW) [19], and Web Processing Service (WPS) [20]. In essence, WMS is used for data visualization; WFS, WCS and SOS for accessing and downloading geographical features, raster data, and sensor observations respectively; CSW for cataloguing and discovery; and WPS for data processing and analysis. In general, these web service specifications are meant to cover common actions (access, discovery, etc.) for geospatial data. They will be widely commented throughout section 3 . 


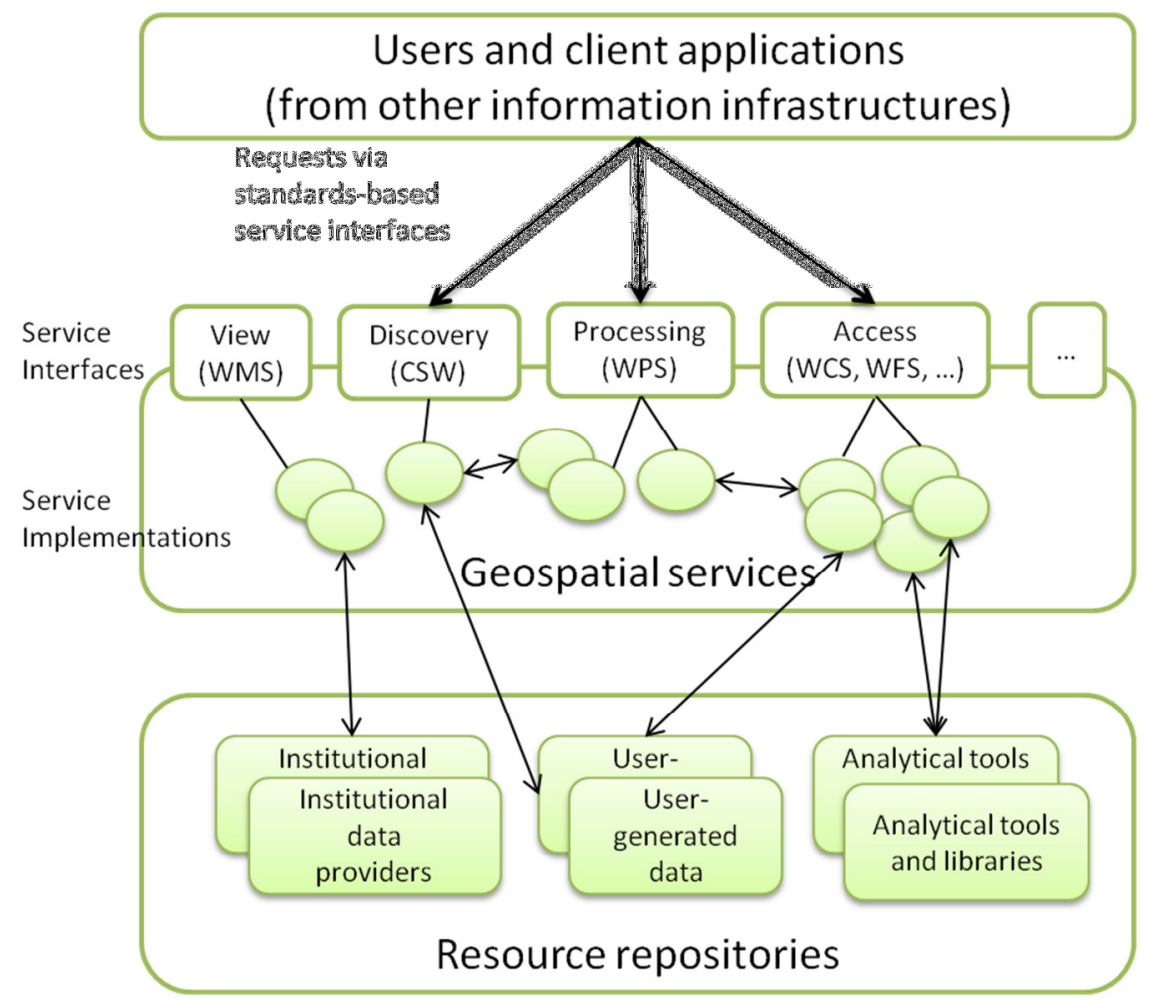

Figure 2. Spectrum of geospatial datasets and services in Glls

In Glls collaboration is a multi-dimensional concept [21]. Data sharing policies represent only one aspect, which should be accompanied with other aspects such as institutional agreements in place and integrated technologies in order to promote collaboration and cooperation among institutions, agencies, users, data providers, and citizens in general. By fostering multidimensional collaboration, Glls provide suitable mechanism to create holistic solutions to multidisciplinary issues. In this paper, we propose to have a close look to on how to bring the benefits and opportunities of Glls into the health domain, since specialized geospatial services in Glls are also desirable in health applications. In the next section we explore how Glls may address geospatial needs in health applications.

\section{Challenges and opportunities}

Consider an infectious disease outbreak such as Tuberculosis (TB) in a city. Public health agencies must make decisions and plan a global strategy in response to this problem. Decisions stem typically from data management activities [22]. In an infectious disease outbreak, however, spatial requirements such as the location of the infected patients become relevant. In this case, data management activities contain modelling disease data, the application of geocoding techniques to find the location of patients, discovery additional data related to the city area needed for further analysis, visualize results in a map, and even publish them in online catalogues or repositories for later use. These activities are represented in Figure 3 and serve us to organize our analysis in this section. Our assumption here is that the infectious disease outbreak scenario poses some geospatial requirements that may be better addressed by Glls. 
Given the costly consequences derived from infectious disease outbreaks, solutions clearly demand an interdisciplinary approach in terms of collaboration between HIls and Glls.

This section identifies challenges and opportunities from the viewpoint of the activities illustrated in Figure 3. For each activity (subsection), we first describe its geospatial dimension and identify challenges for health applications from their geospatial dimension, and then indicate how Glls may overcome them. We stick to the infectious disease outbreak example throughout this section and based our discussion on the use of unitary SWOT analysis for each individual activity in order to evaluate Strengths, Weaknesses, Opportunities, and Threats. In SWOT, strengths and weaknesses are internal factors, while opportunities and threats are external factors. Although SWOT is by nature a subjective analysis, it serves us as a starting point to distinguish between where health applications are placed with and without collaboration with Glls.

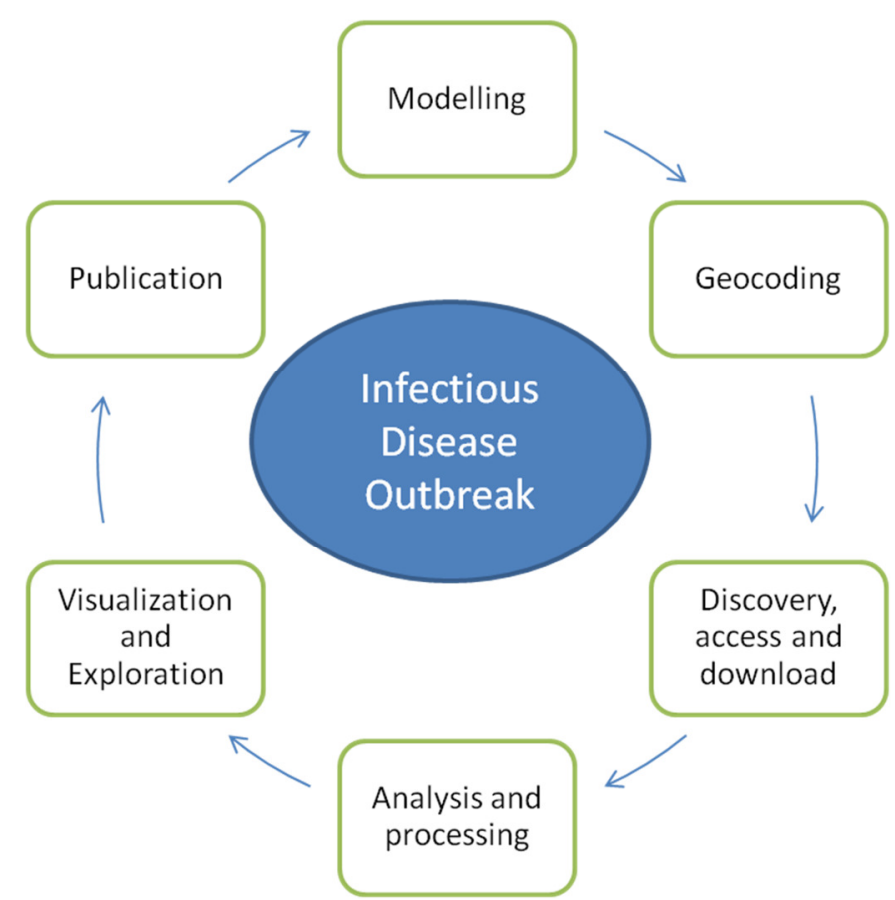

Figure 3. Main activities involved in an infectious disease outbreak (Note that the order in which these activities are carried out may not be always in sequence).

\subsection{Modelling: how to embed geospatial features into health data}

Health data have inherently references to space and time, and thereby it should be captured, analyzed, and studied considering the spatial and temporal dimensions [23, 13]. Take for example a TB case; it refers to a patient record with several properties from which it is relatively easy to encounter some that point to the notion of location or place such as home addresses, district codes, and postal codes. Health data models traditionally suffer a lack of spatial support spatial to properly exploit geospatial capabilities (See Weaknesses in Table 1). For instance, patient records in health databases normally contain textual descriptions concerning places, or at least some kind of internal codification mechanism to refer for instance to districts and 
administrative units. Therefore, smooth and proper combinations of health and geospatial features into appropriate data models would harness existing geospatial analysis tools for generating TB dispersion maps (Section 3.4). Conversely, specific health-related techniques could be absorbed by other domains such as environmental health [24]. Note, for instance, that natural disasters like oil-spills, nuclear disasters, or even earthquakes may lead in a short period to health issues. Hence, the integration of spatio-temporal features into health data sets may accelerate the creation and deployment of cross-domain applications. In essence, enabling bridges between distinct information infrastructures promotes collaboration.

Some works are emerging in this direction. The XML-based HERXML (Health Representation $\mathrm{XML}$ ) [25] schema was designed for the sharing and exchanged of health data together with cartographical representation and the description of associated data sources and statistical methodologies used. HERXML is an attempt to describe the required mapping between health data and how it is represented in a map. The authors developed HERXML emphasize the use of standards-based geospatial services (e.g., WPS services) to access health-related data (See Strengths in Table 1). Curiously, the authors developed HERXML in the context of the Canadian Geospatial Data Infrastructure -a national Gll- to support health programs addressed to local communities.

\begin{tabular}{|c|c|}
\hline $\begin{array}{l}\text { Strengths: } \\
\text { - Health data have inherently } \\
\text { references to space and } \\
\text { time. } \\
\text { - Ongoing efforts on hybrid } \\
\text { data models. }\end{array}$ & $\begin{array}{l}\text { Weaknesses: } \\
\text { - Diversity of health data models. } \\
\text { - Lack of spatial support in current } \\
\text { health data models. }\end{array}$ \\
\hline $\begin{array}{l}\text { Opportunities: } \\
\text { - } \text { Feature-based data model. } \\
\text { - Observation-based data } \\
\text { model. } \\
\text { - Sensor Web and } \\
\text { Observation Web } \\
\text { - } \text { Cross-cutting scenarios. }\end{array}$ & $\begin{array}{l}\text { Threats: } \\
\text { - Disparate of health disciplines. } \\
\text { Waiting for the consensus- } \\
\text { based data models may derive } \\
\text { into a lockout. } \\
\text { - Loss of information in mapping } \\
\text { to a common information model. } \\
\text { - The need to map data models to } \\
\text { approach access interfaces. }\end{array}$ \\
\hline
\end{tabular}

Table 1. A unitary SWOT analysis for data modelling

Glls provide at least two answers to the question "how to embed geospatial features into health data". The first alternative points to the concept of feature in the ISO General Feature Model [26]. In general, a feature is an abstraction of a real world phenomenon such as a building (e.g. patient's home address). Features have properties that describe thematic, spatial or other characteristics associated to a feature. It is the most used data model for representing geographic features in Glls. WFS-based services for instance are based on the feature model. In these cases, users retrieve features (spatial geometries) and its associated properties as 
GML-encoded data [27]. The thematic properties of a feature could be health-related properties such as patient age, genre and type of disease (e.g. TB). Dominkovics et al. [28] have recently explored this possibility by embedding epidemiological data into a feature-based data model to produce spatial density maps of TB concentration. In this case, epidemiological data is associated to a geographical feature, i.e., attributes defining a TB incidence are attached to a geometry (e.g. point or polygon) representing patient's home address.

The second alternative is the observation data model [29]. An observation is in reality a specification of the feature model, i.e., an observation data model inherits from the above feature data model. It contains for example the value of an observation measured and other structured pieces of information such as the unit of measurement, temporal values, domain and spatial contexts, provenance, ownership, quality, uncertainty and process description, among others [30]. Because of its flexibility, the notion of observation seems to better adapt to varying scenarios such as health (See Strengthens in Table 1). The underlying idea is then to treat each piece of health data, a TB case, as an observation that occurs in a location and time (spatiotemporal dimension). Seamless integration between temporal, spatial and health data becomes critical from a multi-scale perspective, where aggregated data is analyzed at different scales. Infectious disease outbreaks are examples of multi-scale modelling because an outbreak spread as time goes by, and one or more initial focuses spread over space to finally connect to each other. Decision makers may take different strategies depending on the scale of the problem. In this context, the observation data model may be much better candidate for a healthspatial data model since it may refer to any geometry type (point, polygon, etc) and explicitly include historic measurements. These characteristics facilitate this kind of dispersion analysis over time. The ongoing $\mathrm{EO} 2 \mathrm{Heaven}{ }^{i}$ project is experimenting in this direction by exploring the use of light-weight versions of observation data models for epidemiological scenarios.

Nevertheless, several technical issues for fitting common health-spatial data model in current geo-spatial database implementations may arise because of the need for greater levels of flexibility and modularity to accommodate a large variety of health data models. Cloud computing combined with new data paradigms such as NoSQL and Big Data are becoming potential solutions to address these issues, particularly to account for spatio-temporal and environmental data management [31, 32, 33, 34, 35]. A recurrent approach in these works is to relax some of the principles in relational databases to allow certain level of data duplication which in turn may lead to better response times and flexible data models.

\subsection{Geocoding: how to get a location for health data}

Emerging infectious diseases are socially and economically costly. Spatial requirements such as the location of each patient are crucial to take actions and adopt a global strategy in response for example to a TB outbreak in a city. As many health emergencies and situations require location, the health community has a large experience in geocoding techniques [36] (see Strengths in Table 2), as demonstrated by the large health-related literature on this topic. In short, geocoding means to transform a place name (e.g. home address) into a well-defined location in terms of geographic coordinates (latitude, longitude) [37]. The use of online commercial geocoding services (e.g., Yahoo! PlaceFinder", ESRI Geocode service ${ }^{\mathrm{iii}}$ ) and other 
volunteered-based initiatives (e.g., opengeocoding.org [38]) is a common approach in most health-related studies that need geocoding tasks.

\begin{tabular}{|c|c|}
\hline $\begin{array}{l}\text { Strengths: } \\
\text { - Most health data already } \\
\text { comes with some kind of } \\
\text { geospatial descriptions. } \\
\text { - Large experience on use of } \\
\text { geocoding techniques. }\end{array}$ & $\begin{array}{l}\text { Weaknesses: } \\
\text { - Variety of access interfaces to } \\
\text { - } \text { online geocoding services. } \\
\text { Specific developed geocoding } \\
\text { client for each different } \\
\text { geocoding service used. } \\
\text { - } \\
\text { Position error in current } \\
\text { geocoding services leads to } \\
\text { variable accuracy on results. }\end{array}$ \\
\hline $\begin{array}{l}\text { Opportunities: } \\
\text { - Gazetteer service become a } \\
\text { "reference" geocoding } \\
\text { service for health services } \\
\text { - Many gazetteer instances } \\
\text { already in place. } \\
\text { - Gazetteer services expose } \\
\text { a standard data model and } \\
\text { service interface. } \\
\text { Gazetteers' responses are } \\
\text { linked and use of semantic } \\
\text { techniques may help in } \\
\text { improving position } \\
\text { accuracy. }\end{array}$ & $\begin{array}{l}\text { Threats: } \\
\text { - Ensure data privacy in the } \\
\text { geocoding process. } \\
\text { - Other health-geospatial models } \\
\text { developed and adopted. } \\
\text { - Other access interfaces } \\
\text { developed and adopted. } \\
\text { - Difficulties in the adoption of } \\
\text { Gazetteer service interface } \\
\text { standard. }\end{array}$ \\
\hline
\end{tabular}

Table 2. A unitary SWOT analysis for geocoding data

From the geospatial perspective, health applications cope with various problems (see Weaknesses in Table 2). First, the great variety of access interfaces provided by these geocoding services provokes that health applications requiring geocoding support are depending on the online geocoding services used. If those online services change or modify their access interfaces, access policies and the like, these health applications must update accordingly. Second, the accuracy of the geocoded data, i.e., the spatial resolution and positional error depends on the geocoding services used. This may have dramatic implications in the subsequent positional analysis as, for example, identification of disease clusters.

Again, Glls provide some solutions in place to cope with the question "how to get a location for health data". For the first case, geocoding is an old issue in the field of geospatial science which has become a basic functionality in Glls [5]. The task of geocoding is covered by so-called gazetteer services which link named features (e.g., place names) with its geographical position and additional associated attributes such as its type and other related features [39]. Gazetteers basically are a kind of databases populated with named features. A gazetteer service then provides a standard service interface to search for locations and place names (see 
Opportunities in Table 2). It may be seen from a technical perspective as a specific application profile of an OGC WFS service [40]. This way WFS-based gazetteer services share a common feature-based data model and a query interface, which greatly facilitates the use of these geocoding services from multiple client applications.

For the second case, the literature regarding the positional accuracy of the geocoding process [41, 42], and the effects of varying the geocoding services used [43, 44] is extensive. Errors in positional accuracy for geocoded addresses are unavoidable and depend on many factors, such as the quality of initial data and the inherent accuracy of commercial geocoding sources used. For instance, a given patient's home address may contain only the district name or code, whereas other may also contain street name and number. Accuracy in the geocoded results depends strongly on the accuracy of the source data. Nevertheless, recent works [45, 43] have found that the process of geocoding of patients' addresses, above all in populated cities, is often very accurate regardless of the geocoding source used.

One of the benefits from using gazetteer services in Glls is that a given entry comes with related data. This means that a result for a place does not return only the position but also other properties such as alternative names and related names. Searching for alternative names for instance may lead to fruitful results since the locality factor (i.e., a same place may have different local names) may make it difficult to find them. In this context, several works have attempted to enrich the quality of gazetteer services by using inference techniques, ontologies and semantic content $[46,47]$, to enhance the precision of geographically vague entries.

In summary, the use of standards-based services for geocoding services such as gazetteer services yields several benefits in terms of collaboration. Health professionals may make use of distinct gazetteer services when geocoded results or the accuracy level are not as expected without the need of adapting health applications that use them. In essence, standardization facilitates collaboration. The promotion of standardized access for geocoding services from the health community is feasible by promoting gazetteer services as "reference" geocoding services. For instance, the UN/EC Common Gazetteer Searchiv service may become a relevant example for the health community.

\subsection{Discovery and access: how to find health data in a given area}

Data discovery, access and download are basic services in most information infrastructures [48]. In the health domain, there exist some examples of discovery services [49] and access interfaces for online health-related resources and services ${ }^{v}$. However, as online geocoding services seen in Section 3.2, the diversity of access and discovery interfaces is yet the common pattern.

Like previous challenges -modelling and geocoding- discovery services and tools for healthrelated resources still lack a proper support for spatio-temporal search criteria (See Weaknesses in Table 3). This is due in part by the lack of spatial features in health data models (Section 3.1) that makes it necessary a big effort to adapt and geocode health data (Section 3.2). In essence, the same rationale exposed earlier, i.e. to reinforce collaboration with other 
specialized services to meet such needs, also applies to spatial-based queries exemplified by the section heading "to find health data in a given area".

\begin{tabular}{|c|c|}
\hline $\begin{array}{l}\text { Strengths: } \\
\text { - Health data and resources } \\
\text { available online. } \\
\text { - Meta-search engines in } \\
\text { health domain. } \\
\text { - Web API access. }\end{array}$ & $\begin{array}{l}\text { Weaknesses: } \\
\text { - Lack of spatial-based search } \\
\text { criteria. } \\
\text { - Lack of spatially-aware health } \\
\text { data models. } \\
\text { - Lack of open standards. }\end{array}$ \\
\hline $\begin{array}{l}\text { Opportunities: } \\
\text { - Strong support on standard } \\
\text { bodies (OGC, ISO). } \\
\text { - } \text { Availability of operational } \\
\text { geospatial services such as } \\
\text { CSW, WFS, WCS, and } \\
\text { SOS (see Figure 2). } \\
\text { - Established links to other } \\
\text { domains such as } \\
\text { environmental and } \\
\text { meteorological. }\end{array}$ & $\begin{array}{l}\text { Threats: } \\
\text { - Security and authentication. } \\
\text { - Other health-geospatial models } \\
\text { developed and adopted. } \\
\text { - Lack of awareness of services } \\
\text { for geospatial data discovery, } \\
\text { access and download. }\end{array}$ \\
\hline
\end{tabular}

Table 3. A unitary SWOT analysis for data discovery and access

Geospatial data discovery, access and download are widely covered in Glls. OGC standards such as CSW for discovery as well as WFS, WCS and SOS for data access and download can be used in health applications. If TB data were modelled using the observation data model, an array of temporal and spatial filtering parameters such as observed phenomena (e.g. TB or AIDS disease, location (e.g. district, city), time intervals (e.g. two weeks) and instants [18].

In addition, such discovery, access and download services are mostly created, deployed and maintained under legal and mandatory directives like INSPIRE (Infrastructure for Spatial Information in Europe)[50]. Public administrations and organizations that manage INSPIRE data themes ${ }^{\mathrm{vi}}$ are then committed to ensure the long-term provision of these services. Indeed, the adoption of geospatial services for data discovery and access in other application domains supports this trend $[51,52]$. This means that health applications may also benefit from these geospatial services without much effort. As most institutions like city councils serve their geospatial data using these standards-based services, health applications for example might discovery and fetch related datasets (i.e., layers) such as population density, points of interests, water faculties, schools and so on in a given into their analysis on the study area (Section 3.5).

Standardization enhances interoperability and is a determining factor to enable collaboration between infrastructures. Indeed, it is much easier to maintain and improve health applications if they use operational services deployed on Glls. Specialized health services or applications can be then developed in less time, because required spatial functionalities are delegated to the underlying geospatial services. In this context, Vacarri et al. [53] recently presented the 
EuroGEOSS broker vii, a web component based on brokering and mediation capabilities to facilitate uniform discovering and accessing to heterogeneous resources from diverse domains such as forestry, biodiversity, and drought. Extrapolating the EuroGEOSS brokering approach to health domain would be certainly feasible yet based on mediated and integrated data models as those commented in Section 3.1. On the other side, the integration of disparate data models such as those coming from environment and health must be done under the control of semanticaware mechanisms to guarantee its complete interoperability. Last but not least the security constraint is a big issue when managing health data, in this context Glls provide mechanisms to secure data access although more research has to be done in this direction.

\subsection{Analysis: how to spatially cluster health data}

Most health-related data is natively aggregated. For example public health agencies yearly report on in the total number and rates of (TB) cases at district, city or even region level. This gets even worse when health data must be integrated with other kinds of data sets that are aggregated at different scale. Consider census data that is commonly aggregated by census tract whereas mortality rates in a given city by district area or administrative unit. Distinct scales such as census tracts and city districts pose important issues when health applications combine and process data aggregated at different scales (See Weaknesses in Table 4).

Spatial aggregation or clustering is a kind of aggregation that takes space as a vertebral dimension to group data. Spatially aggregated data is commonplace in geospatial applications. Some data (e.g., number of diseases, population at risk) are summarized by regions or administrative units, i.e., in spatial clusters. In this context, new methods to compute clusters in spatially aggregated health data and identify multiple variable associations have been recently proposed [54, 55]. For TB data analysis, this kind of spatial clustering may ease the identification of "hot spots" (e.g. part of a district) where the incidence of TB cases is greater than on average.

\begin{tabular}{|c|c|}
\hline $\begin{array}{l}\text { Strengths: } \\
\qquad \quad \text { Health data comes natively } \\
\text { aggregated. }\end{array}$ & $\begin{array}{l}\text { Weaknesses: } \\
\text { - } \\
\text { Diversity of levels of } \\
\text { aggregations and scales. } \\
\text { - } \text { Lack of service interface for } \\
\text { health data processing. }\end{array}$ \\
\hline $\begin{array}{l}\text { Opportunities: } \\
\text { - Proven OGC WPS services } \\
\text { for multiple functionalities. } \\
\text { - Other OGC specifications in } \\
\text { the realm of Sensor Web } \\
\text { may help in data } \\
\text { processing. } \\
\text { - Cross-cutting scenarios. }\end{array}$ & $\begin{array}{l}\text { Threats: } \\
\text { - Security and authentication. } \\
\text { - Diversity of underlying health } \\
\text { data models. } \\
\text { - Semantic heterogeneity. }\end{array}$ \\
\hline
\end{tabular}

Table 4. A unitary SWOT analysis for data analysis 
Glls again contemplate geospatial data processing and aggregation services that support the above spatially clustering requirements in health (see Opportunities in Table 4). The OGC WPS service interface is specifically aimed to data processing and analysis. Several examples in the literature have proven the value of WPS services to process any kind of environmental and geospatial data [56]. In the health domain, however, examples using WPS services are still scarce but pave the way for strengthening collaboration to other infrastructures (e.g. Glls). For instance, Gao et al. [25] describe the use of WPS-based services to access to HERXMLencoded health data. Dominkovics et al. [28] have also implemented geoprocessing services to process dynamically dispersion maps for TB data. Stasch et al. [57] present an approach for spatio-temporal aggregation of heterogeneous observations that differ in spatio-temporal coverage and resolution using geoprocessing services. In summary, these recent experiments suggest that, combined with a suitable data model as described in Section 3.1, WPS services deployed on Glls may serve to carry out spatial aggregation and clustering for health data.

\subsection{Visualization: how to show health data and related datasets in a map}

Data visualization allows users to browse and explore data for new insights and patterns. Data visualization mostly involves datasets coming from different sources. While displaying georeferenced TB data in a map certainly helps health professionals, new insights may emerge for instance to identify associated risk factors when TB data is blended with complementary datasets such as level of population and poverty rates and altogether represented in a map. That is, representing information in a map, when appropriate, offers new perspectives for analysis and decision-making processes. This strengthens collaboration between involved stakeholders, institutions and data providers since health issues require data from various information infrastructures.

\begin{tabular}{|c|c|}
\hline $\begin{array}{l}\text { Strengths: } \\
\text { - Easy development. } \\
\text { - Web based interaction. } \\
\text { - Heath-related mapping } \\
\text { mashup applications. }\end{array}$ & $\begin{array}{l}\text { Weaknesses: } \\
\text { - Data heterogeneities. } \\
\text { - Data inconsistencies. } \\
\text { - Difficulties in integration and } \\
\text { reuse. }\end{array}$ \\
\hline $\begin{array}{l}\text { Opportunities: } \\
\text { Exploitation of map-based } \\
\text { and virtual-based interfaces } \\
\text { for data exploration and } \\
\text { visualisation. } \\
\text { - Spatio-temporal data } \\
\text { visualization tools (e.g. city } \\
\text { models viewer) for } \\
\text { supporting informed } \\
\text { decision-making processes }\end{array}$ & $\begin{array}{l}\text { Threats: } \\
\text { - Credibility about authors and } \\
\text { data. } \\
\text { - Data privacy. } \\
\text { - Virtual globes tools and } \\
\text { applications still in their infancy. }\end{array}$ \\
\hline
\end{tabular}

Table 5. A unitary SWOT analysis for data visualization and exploration 
Web mapping applications allows developers to merge and visualize health and spatial data in a map. These applications are commonly implemented as mashup applications that integrate heterogeneous information from diverse web services and online sources. In turn, aggregated information resulted from a mashup application might be used for creating new sophisticated mashup applications and services. Mashup application can easily visualize health-related data in its geographical context (see Strengths in Table 5). For example, healthmap.org ${ }^{\text {viii }}$ is an online mash-up application that monitors public health threats coming from formal and informal sources such as Google News, Baidu and others, and shows aggregated results in a map. Cheung et al. [58] described a mapping mashup application that integrates health and life sciences data through a map-based interface using different Web 2.0 technologies and services. Gao et al [59] discussed some concrete challenges in disease mapping as data heterogeneities, difficulties in integration and reusability, lack of interoperability between different services and concerns over the representation of data. The authors encouraged to look towards standards-based services to overcome these challenges.

The response to the question "how to show health data and related datasets in a map" we posed in this section goes in the same direction. Data visualization has been long studied in geographical information sciences [60]. These foundations have been partly shaped in Glls as a set of standards-based service interfaces for geospatial data visualization. A remarkable example is the OGC WMS service interface, a kind of portrayal service specialized in visualizing geospatial information on map viewers. To this respect, Kamel Boulos and Honda [61] generated health maps by retrieving geospatial layers from remote WMS services. KML [62] has also been determining to enable the proliferation of mapping mashup applications [63, 64]. In essence, geospatial services for data visualization such as WMS and accompanying standards (e.g. KML, etc.) make it viable to add other thematic data to health analysis. As many institutions and organizations expose their datasets using those services (as part of the INSPIRE directive), cadastral, demographics, and even population statistics are made available through WMS services. This certainly gives value to use these services in health.

Although map-based interfaces have been traditionally the preferred manner for user interface and interaction, recent advances in communication and mobile technologies are changing this situation [65]. Tools for rendering virtual scenes of detailed city models and landscapes showing data on its geographical context are now appearing [66], which as a side-effect promote a better understanding of spatial-contextualized data [67]. Imagine the ability to face health issues (e.g. air pollution, $\mathrm{CO} 2$, noise) by interacting in user-friendly manner with 3D city models fed with spatial-contextualized data. Virtual globes represent a first step towards this vision [68]. Google Earth is one of the most popular virtual globes and it is being used in various geospatial health applications. Stensgaard et al. [69] discuss its usage in a public health scenario in Africa which aimed to control and monitor a disease transmission. The NASA World Wind globe (NWW ${ }^{\mathrm{ix}}$ ) is another popular virtual globe that has been proven in visualizing earth observation data and simulation [70]. As long as virtual globes incorporate advanced visualization and spatial analysis tools [71, 60 ] as well as suitable means for user participation and collaboration, these tools will 
increasingly become the default interaction environment from Glls point of view and likely in health applications too.

Friendly and easy-to-use interfaces enable greater levels of user interaction and participation, and support a variety of stakeholders and scenarios. Indeed, users are naturally inclined and know how to use map-based interfaces, which are an intrinsic part in geospatial visualization and exploration tools (see Opportunities in Table 5). We believe that maps- and virtual globesbased interfaces are a powerful means to enable collaboration and participation between stakeholders in health (Section 3.6). This kind of interfaces may also allow a better integration with mainstream media data (pictures, videos, etc.) and social networking services. In reality, anything (infectious disease, natural hazards, tweets, etc) happens in a place [72].

\subsection{Publication: citizens may help in disease outbreaks}

The traditional view of the concept of social networks has been long linked with health services. Different studies have analyzed experiences and roles of patients within their social networks $[73,74,75]$. Nevertheless, we are interested here in the recent wave of online social networking services and applications that allow people to socialize and exchange personal and professional information on the Web $[76,77]$. Citizens propelled by social networking services are increasingly participating in the process of generating social data and collaborating with others in solving-problem tasks. User as data producer has been also reflected in the geospatial domain known as Volunteered Geographic Information (VGI) [78]. VGI highlights the importance of users as active producers of geographic information rather than passive recipients (see Strengths in Table 6). Indeed social networking services are increasingly moving to locationbased social networking services [79], pointing out the importance of location for citizens. Ethical and privacy considerations aside [80], the increasing amount of VGI together with the need to develop healthier cities have unlocked a new breed of health applications that emphasize the importance of "health voluntarism" for the health community [81]. Citizens providing health data to track diseases in cities [82], citizens with data and mapping tools to actively participate in shaping the city ${ }^{x}$, and citizens with health care mobile applications to facilitate access to the scarcity of health human resources in Africa ${ }^{\mathrm{xi}}$, are some recent examples on how "citizens may help in disease outbreaks" (e.g., Outbreaksnearme ${ }^{\mathrm{xi}}$ ).

Nevertheless, the ability to engage citizens is a critical aspect to leverage VGI applications in health [64]. Lowering the barriers to ease user participation is one of the major issues in Glls to smoothly integrate VGI data with institutional data from GII [83, 84]. We believe that a key point to engage citizens is to provide easy mechanisms to (re-)publish VGI data into Glls [85]. For example, Nuñez-Redó et al. [86] explored interoperable mechanisms to retrieve crowd-sourced information from multiple social networking services to be integrated with geospatial resources in the realm of Glls. Díaz et al. [87] explored geospatial services for data publication in Glls from desktop applications, social networking services, and even resulting data from analysis. In any case, published VGI content was shared and made it widely available using standard-based geospatial services (Section 2). 


\begin{tabular}{|l|l|}
\hline $\begin{array}{l}\text { Strengths: } \\
\text { - Each individual is potentially } \\
\text { a data producer. }\end{array}$ & $\begin{array}{r}\text { Weaknesses: } \\
\text { - }\end{array}$ \\
$\begin{array}{l}\text { Social networks dynamics } \\
\text { could be crucial in health } \\
\text { monitoring and early alert. }\end{array}$ & $\begin{array}{l}\text { Loluntarism. } \\
\text { Data privacy treatment. }\end{array}$ \\
\hline $\begin{array}{l}\text { Opportunities: } \\
\text { Shift to location-based } \\
\text { social networks. } \\
\text { VGl-related projects already } \\
\text { in place. }\end{array}$ & $\begin{array}{r}\text { Threats: } \\
\text { Cross-cutting scenarios. }\end{array}$ \\
$\quad$
\end{tabular}

Table 6. A unitary SWOT analysis for data publication

In VGI, any individual may produce and published timely data that may be exploited in health applications. Furthermore the location-based characteristic and huge volume of data generated directly by citizens open the door to new health applications such as real-time monitoring of health issues and events in delimited areas with a high spatial and temporal resolution, offering the opportunity to shorten response time. Glls principles could be leveraged in order to facilitate health data publication generated both by official organizations and by citizens. Data publication mechanisms in Glls increase notably the availability of data to be efficiently shared [87].

\section{Concluding remarks}

Current frameworks for collaborative health development still suffer from a lack of support of spatio-temporal features, restrictions on scalability, and show uncertainties regarding data sharing and interoperability [88]. These issues can be addressed by defining a better collaboration strategy early in the development of health infrastructures, services, and technologies. The main advantage of using Glls is that is an operational infrastructure already in place whose Gll drivers can be easily realigned to deal with health-related data. Glls drivers support for spatio-temporal and health data models, existing infrastructure-enabling services based on standards-based service interfaces, spatial-enabled user interfaces and powerful geovisualization and geo-analytics tools, and user-generated data provision mechanisms- may be used as a basis to create and deploy advanced health applications.

Glls encompass institutional (e.g., people, policies and agreements) and technological aspects (e.g., standards, data, protocols) [5]. The institutional part or social infrastructure comprises communities of service providers, developers, researchers, public administrations and citizens interested in geospatial resources. The technical part or technological infrastructure refers to the supporting platform for integrating different services, data, technologies, and tools into a collaborative environment. Both kinds of infrastructures, social and technological, are necessary ingredients that have to be interrelated to enable Gll infrastructures and support spatial data applications in different domains. Essentially, collaborative health services also require a 
smoothly integration between social and technological infrastructures. In this paper we have only focused on the technology, though, social and institutional aspects are equally crucial for building successfully collaborative health applications.

Unfortunately, some remarkable obstacles need to be regarded to bring Glls to the full potential in health-related domains. Firstly, ensuring security and privacy are strong requirements in collaborative health systems and applications [89]. To keep patients' privacy is a big issue in health [90]. Secondly, as mentioned earlier, promoting and fostering a community of involved stakeholders from service providers, to health practitioners and researchers, to healthcare organizations and citizens is a must to put in practice collaborative health applications and supporting infrastructures [91].

In summary, Glls in terms of social and technological aspects may help to determine a holistic strategy by involving all important stakeholders in a collaborative effort to contribute in the development of a new wave of health applications and supporting collaborative information infrastructures in multitude of environmental-health-spatial applications. 


\section{References}

[1] G.M. Olson, The next generation of science collaboratories, presented at the International Symposium on Collaborative Technologies and Systems, IEEE Press, Baltimore, USA, 2009.

[2] T. Hey, A.E. Trefethen, Cyberinfrastructure for e-science, Science 308 (2005) 817-821.

[3] N. Pearce, A.H. Smith, Data sharing: not as simple as it seems, Environmental Health 10(107) (2011).

[4] C. Yang, R. Raskin, M. Goodchild, M. Gahegan, Geospatial cyberinfrastructure: past, present and future, Computers, Environment and Urban Systems 34(4) (2010) 263-358.

[5] I. Masser, GIS Worlds: Creating Spatial Data Infrastructures, ESRI Press, Redlands, 2005.

[6] J. Thompson, S. Eagleson, P. Ghadirian, A. Rajabifard, SDI for collaborative health services planning, presented at the Global Spatial Data Infrastructures World Conference, Rotterdam, The Netherlands, 2009.

[7] M.F. Goodchild, P. Fu, P. Rich, Sharing Geographic Information: An Assessment of the Geospatial One-Stop, Annals of the Association of American Geographers 97(2) (2007) 250266.

[8] M. Hunink, P. Glasziou, J. Siegel, J. Weeks, J. Pliskin, A. Elstein, M. Weinstein, Decision Making in Health and Medicine: Integrating Evidence and Values, Cambridge University Press, Cambridge, 2001.

[9] C.A. Davis Jr., F.T. Fonseca, G. Câmara, Beyond SDI: integrating science and communities to create environmental policies for the sustainability of the Amazon, International Journal of Spatial Data Infrastructures Research 4 (2009) 156-174.

[10] G. Harris, Integrated assessment and modelling: an essential way of doing science, Environmental Modelling and Software 17 (3) (2002) 201-207.

[11] S.L. Cutter, GI Science, Disasters, and Emergency Management, Transactions in GIS 7(4) (2003) 439-446.

[12] M.N. Kamel Boulos, Towards evidence-based, GIS-driven national spatial health information infrastructure and surveillance services in the United Kingdom, International Journal of Health Geographics 3(1) (2004).

[13] M.N. Kamel Boulos, Geographic information systems and the spiritual dimension of health: a short position paper, International Journal of Health Geographics 2(6) (2003). 
[14] T. Mathys, M.N. Kamel Boulos, Geospatial resources for supporting data standards, guidance and best practice in health informatics, BMC Research Notes 4(19) (2011).

[15] OGC, OpenGIS Web Map Server Implementation Specification, version 1.3.0, OpenGIS Implementation Specification, Open Geospatial Consortium, 2006.

[16] OGC, OpenGIS Web Feature Service 2.0 Interface Standard, version 2.0.0, OGC Implementation Standard, Open Geospatial Consortium, 2010.

[17] OGC, OGC WCS 2.0 Interface Standard - Core, version 2.0.0, OGC Interface Standard, Open Geospatial Consortium, 2010.

[18] OGC, OpenGIS Sensor Observation Service OGC Implementation Standard, Open Geospatial Consortium, 2007.

[19] OGC, OpenGIS Catalogue Services Specification, Version 2.0.2, OGC Implementation Specification, Open Geospatial Consortium, 2007.

[20] OGC, OpenGIS Web Processing Service (WPS), version 1.0.0. OGC Standard, Open Geospatial Consortium, 2007.

[21] K. Schmidt, Cooperative Work and Coordinative Practices: Contributions to the Conceptual Foundations of Computer Supported Cooperative Work (CSCW), first ed., Springer, London, 2011.

[22] T.S. Parikh, K. Chen: Data Management for Meeting Global Health Challenges, Proceedings of the VLDB 4(12) (2011) 1514.

[23] S. Cummins, S. Curtis, A.V. Diez-Roux, S. Macintyre, Understanding and representing 'place' in health research: A relational approach, Social Science and Medicine 65(9) (2007) 1825-1838.

[24] R.S. Kovats, C.D. Butler, Global health and environmental change: linking research and policy, Current Opinion in Environmental Sustainability 4(1) (2012) 44-50.

[25] S. Gao, D. Mioc, X. Yi, F. Anton, E. Oldfield, D.J. Coleman, Towards web-based representation and processing of health information, International Journal of Health Geographics 8(3) (2009).

[26] ISO 19109:2005, ISO Geographic information -- Rules for application schema, International Organization for Standardization, 2005.

[27] OGC, OpenGIS Geography Markup Language (GML) Encoding Standard, version 3.2.1, OGC Standard, Open Geospatial Consortium, 2007. 
[28] P. Dominkovics, C. Granell, A. Pérez-Navarro, M. Casals, A. Orcau, J.A. Caylà, Development of spatial density maps based on geoprocessing web services: application to tuberculosis incidence in Barcelona, Spain, International Journal of Health Geographics 10(62) (2011).

[29] OGC, Observations and Measurements - XML Implementation, version 2.0, OGC Implementation, Open Geospatial Consortium, 2011.

[30] D. Havlik, S. Schade, Z.A. Sabeur, P. Mazzetti, K. Watson, A.J. Berre, J.L. Mon, From Sensor to Observation Web with Environmental Enablers in the Future Internet, Sensors 11(4) (2011) 3874-3907.

[31] C. S. Baptista, O. F. Lima, M. G. Oliveira, F. G. Andrade, T. E. Silva, C. E. E. Pires, Using OGC Services to Interoperate Spatial Data Stored in SQL and NoSQL Databases, presented at the Proceedings of the $12^{\text {th }}$ GEOINFO Conference, Campos do Jordão, Brazil, 2011.

[32] J.D. Blower, GIS in the Cloud: Implementing a Web Map Service on Google App Engine, presented at the Proceedings of the 1st International Conference and Exhibition on Computing for Geospatial Research \& Application, Washington D.C., 2010.

[33] G. Giuliani, N. Ray, A. Lehmann, Grid-enabled Spatial Data Infrastructure for environmental sciences; Challenges and opportunities, Future Generation Computer Systems 27(3) (2011) 292-303.

[34] C. Yang, H. Wu, Q. Huang, Z. Li, J. Li, Using Spatial Principles to Optimize Distributed Computing for Enabling the Physical Science Discoveries, Proceedings of the National Academy of Sciences 108(14) (2011) 5498-5503.

[35] C. Yang, M. Goodchild, Q. Huang, D. Nebert, R. Raskin, Y. Xu, M. Bambacus, D. Fay, Spatial Cloud Computing: How can the Geospatial Sciences use and Help Shape Cloud Computing?, International Journal of Digital Earth 4(4) (2011) 305-329.

[36] F.P. Boscoe, The Science and Art of Geocoding, In: G. Rushton M.P. Armstrong, J. Gittler, B.R. Greene, C.E. Pavlik, M.M West, D.L. Zimmerman *Eds.), Geocoding Health DataThe Use of Geographic Codes in Cancer Prevention and Control, Research, and Practice, CRC Press, Boca Raton FL, 2008, pp. 95-109.

[37] M.F. Goodchild, Formalizing place in geographic information systems, in: L. M.Burton et al. (Eds), Communities, neighborhoods, and health: expanding the boundaries of place, Springer, New York, 2011, pp. 21-35.

[38] F.-J. Behr, A. Rimayanti, OPENGEOCODING.ORG - A free, participatory, community oriented Geocoding Service, presented at The International Archives of the Photogrammetry, Remote Sensing and Spatial Information Sciences, XXXVII, Part B4, 2008. 
[39] M.F. Goodchild, L.L. Hill, Introduction to digital gazetteer research, International Journal of Geographical Information Science 22(10) (2008) 1039-1044.

[40] OGC, OGC Best Practices Document: Gazetteer Service -Application Profile of the Web Feature Service, Candidate Implementation Standard, Open Geospatial Consortium, 2011.

[41] M.R. Cayo, T.O. Talbot, Positional error in automated geocoding of residential addresses, International Journal of Health Geographics 2(10) (2003).

[42] D.W. Goldberg, J.P. Wilson, C.A. Knoblock, B. Ritz, M.G. Cockburn, An effective and efficient approach for manually improving geocoded data, International Journal of Health Geographics 7(60) (2008).

[43] D. Roongpiboonsopit, H.A. Karimi, Comparative evaluation and analysis of online geocoding services, International Journal of Geographical Information Science 24(7) (2010) 1081-1100.

[44] E.A. Whitsel, P.M. Quibrera, R.L. Smith, D,J. Catellier, D. Liao, A.C. Henley, G. Heiss, Accuracy of commercial geocoding: assessment and implications, Epidemiologic Perspectives \& Innovations 3(82) (2006).

[45] M.R. Bonner, D. Han, J. Nie, P. Rogerson, J.E. Vena, J.L. Freudenheim, Positional accuracy of geocoded addresses in epidemiologic research, Epidemiology 14 (2003) 408-412.

[46] Q. Guo, Y. Liu, J. Wieczorek, Georeferencing locality descriptions and computing associated uncertainty using a probabilistic approach, International Journal of Geographical Information Science 22(10) (2008) 1067-1090.

[47] C. B. Jones, R. S. Purves, P. D. Clough, H. Joho, Modelling vague places with knowledge from the Web, International Journal of Geographical Information Science 22(10) (2008) 1045-1065.

[48] S. Krishnan, K. Bhatia, SOAs for scientific applications: experiences and challenges, Future Generation Computer Systems 25(4) (2009) 466-473.

[49] S. Sastre-Suárez, E. Pastor-Ramon, Evaluation of free metasearch engines specialized in health sciences, El Profesional de la Información 20(6) (2011) 639-644.

[50] INSPIRE, Directive 2007/2/EC of the European Parliament and of the Council of 14 March 2007 establishing an Infrastructure for Spatial Information in the European Community (INSPIRE), Official Journal of the European Union, L 108/1, Volume 50, 25 April 2007. http://eur-lex.europa.eu/JOHtml.do?uri=OJ:L:2007:108:SOM:EN:HTML.

[51] C. Granell, L. Díaz, M. Gould, Service-oriented applications for environmental models: reusable geospatial services, Environmental Modelling and Software 25 (2) (2010) 182-198. 
[52] D. Lowe, A. Woolf, B. Lawrence, S. Pascoe, Integrating the Climate Science Modelling Language with geospatial software and services, International Journal of Digital Earth 2(Supplement 1) (2009) 29-39.

[53] L. Vaccari, M. Craglia, C. Fugazza, S. Nativi, M. Santoro, Integrative Research: The EuroGEOSS Experience, IEEE Journal of Selected Topics in Applied Earth Observations and Remote Sensing (2012) doi:10.1109/JSTARS.2012.2190382.

[54] K. Buchin, M. Buchin, M. van Kreveld, M. Löffler, J. Luo, R.I. Silveira, Processing aggregated data: the location of clusters in health data, Geoinformatica 16(3) (2012) 497-521.

[55] D.G. Leibovici, L. Bastin, S. Anand, G. Hobona, M. Jackson, Spatially Clustered Associations in Health Related Geospatial Data, Transactions in GIS 15(3) (2011) 347-364.

[56] P. Zhao, T. Foerster, P. Yue, The Geoprocessing Web, Computers \& Geosciences 47 (2012) 3-12.

[57] C. Stasch, T. Foerster, C. Autermann, E. Pebesma, Spatio-temporal aggregation of European air quality observations in the Sensor Web, Computers \& Geosciences 47 (2012) 111-118.

[58] K.-H. Cheung, K.Y. Yip, J.P. Townsend, M. Scotch, HCLS 2.0/3.0: Health care and life sciences data mashup using Web 2.0/3.0, Journal of Biomedical Informatics 41(5) (2008) 694705.

[59] S. Gao, D. Mioc, F. Anton, X. Yi, D.J. Coleman, Online GIS services for mapping and sharing disease information, International Journal of Health Geographics 7(8) (2008).

[60] G. Andrienko, N. Andrienko, U. Demsar, D. Dransch, J. Dykes, S. Fabrikant et al., Space, time and visual analytics, International Journal of Geographical Information Science 24(10) (2010):1577-600.

[61] M.N. Kamel Boulos, K. Honda, Web GIS in practice IV: publishing your health maps and connecting to remote WMS sources using the Open Source UMN MapServer and DM Solutions MapLab, International Journal of Health Geographics 5(6) (2006).

[62] OGC, OGC KML, version 2.2.0, OGC Standard, Open Geospatial Consortium, 2008.

[63] M.N. Kamel Boulos, Web GIS in practice III: creating a simple interactive map of England's Strategic Health Authorities using Google Maps API, Google Earth KML, and MSN Virtual Earth Map Control, International Journal of Health Geographics 4(2) (2005).

[64] E. Tate, C.G. Burton, M. Berry, C.T. Emrich, S.L. Cutter, Integrated Hazards Mapping Tool, Transactions in GIS 15(5) (2011) 689-706. 
[65] A. Schmidt, B. Pfleging, F. Alt, A. Sahami, G. Fitzpatrick, Interacting with $21^{\text {st }}$ Century Computers, IEEE Pervasive Computing 11(1) (2012) 22-31.

[66] L. Polepeddi, E. Barden, Three-dimensional modeling of a primary health care clinic in Ho, Ghana: its contribution to student engagement, fundraising, and program planning, Global Health Action 3(5060) (2010).

[67] M-P Kwan, J. Lee, Geovisualization of human activity patterns using 3D GIS: a timegeographic approach, in: M.F. Goodchild, D. Janelle (Eds), Spatially Integrated Social Science: Examples in Best Practice, Oxford University Press, Oxford, 2004, pp. 48-66.

[68] B.T. Tuttle, S. Anderson, R. Huff, Virtual globes: An Overview of Their History, Uses, and Future Challenges, Geography Compass 2(5) (2008) 1478-1505.

[69] A.S. Stensgaard, C.F.L. Saarnak, J. Utzinger, P. Vounatsou, C. Simoonga, G. Mushinge, C. Rahbek, F. Møhlenberg, T.K. Kristensen, Virtual globes and geospatial health: the potential of new tools in the management and control of vector-borne diseases, Geospatial Health 3(2) (2009) 127-141.

[70] A. Beltran, C. Abargues, C. Granell, M. Nuñez, L. Díaz, J. Huerta, A virtual globe tool for searching and visualizing geo-referenced media resources in social networks, Multimedia Tools \& Applications (2013) doi: 10.1007/s11042-012-1025-0.

[71] N. Andrienko, G. Andrienko, P. Gatalsky, Exploratory spatio-temporal visualization: An analytical review, Journal of Visual Languages \& Computing 14(6) (2003) 503-541.

[72] Nature Editorial, A place for everything, Nature 453(2) (2008) 2.

[73] K. Gayen, R. Raeside, Social networks, normative influence and health delivery in rural Bangladesh, Social Science and Medicine 65(5) (2007) 900-914.

[74] E. Jippes, M.C. Achterkamp, P.L.P. Brand, D. Jan Kiewiet, J. Pols, J.M.L. van Engelen, Disseminating educational innovations in health care practice: Training versus social networks, Social Science and Medicine 70(10) (2010) 1509-1517.

[75] D. Meltzer, J. Chung, P. Khalili, E. Marlow, V. Arora, G. Schumock, R. Burt, Exploring the use of social network methods in designing healthcare quality improvement teams, Social Science and Medicine 71(6) (2010) 1119-1130.

[76] J.L. Bender, M.-C. Jimenez-Marroquin, A.R. Jadad, Seeking Support on Facebook: A Content Analysis of Breast Cancer Groups, Journal of Medical Internet Research 13(1) (2011):e16. 
[77] N.K. Cobb, A.L. Graham, M.J. Byron, D.B. Abrams et al, Online Social Networks and Smoking Cessation: A Scientific Research Agenda, Journal of Medical Internet Research 13(4) (2011):e119.

[78] M.F. Goodchild, Citizens as Voluntary Sensors: Spatial Data Infrastructure in the World of Web 2.0, International Journal of Spatial Data Infrastructures Research 2 (2007) 24-32.

[79] D.Z. Sui, M.F. Goodchild, The convergence of GIS and social media: challenges for GIScience, International Journal of Geographical Information Science 25(11) (2011) 1737-1748.

[80] L.A. Thompson, E. Black, W.Patrick Duff, N. Paradise Black, H. Saliba, K. Dawson, Protected Health Information on Social Networking Sites: Ethical and Legal Considerations, Journal of Medical Internet Research 13(1) (2011) e8.

[81] J.A. Olson, Health-Related Geospatial Data and Social Media: Can You Harvest Geosocial Data?, Journal of Map \& Geography Libraries 7(3) (2011) 377-381.

[82] M.W. Skinner, A. Power, Voluntarism, health and place: Bringing an emerging field into focus, Health \& Place 17(1) (2011) 1-6.

[83] M. Craglia, Volunteered Geographic Information and Spatial Data Infrastructures: when docparallel lines converge?, presented at the Specialist Meeting on Volunteered Geographic Information, Santa Barbara, USA, 2007.

[84] M. Gould, Vertically interoperable geo-infrastructures and scalability, presented at the Specialist Meeting on Volunteered Geographic Information, Santa Barbara, USA, 2007.

[85] L. Díaz, S. Schade, GEOSS Service Factory: Assisted Publication of Geospatial Content, in: S. Geertman, W. Reinhardt, F. Toppen (Eds.), Advancing Geoinformation Science for a Changing World, Berlin, Springer, 2011, pp. 423-442.

[86] M. Núñez-Redó, L. Díaz, J. Gil, D. González, J. Huerta, Discovery and Integration of Web 2.0 Content into Geospatial Information Infrastructures: A Use Case in Wild Fire Monitoring, presented at the Proceedings of the IFIP WG 8.4/8.9 international cross domain conference on Availability, reliability and security for business, enterprise and health information systems, 2011, pp. 50-68.

[87] L. Díaz, C. Granell, M. Gould, J. Huerta, Managing user generated information in geospatial cyberinfrastructures, Future Generation Computer Systems 27 (3) (2011) 304-314.

[88] M. van Limburg, J.E.W.C. van Gemert-Pijnen, N. Nijland, H.C. Ossebaard, R.M.G Hendrix, E.R Seydel, Why Business Modeling is Crucial in the Development of eHealth Technologies, Journal of Medical Internet Research 13(4) (2011) e12. 
[89] A.G. West, J. Chang, K.K. Venkatasubramanian, I. Lee, Trust in collaborative web applications, Future Generation Computer Systems, 28(8) (2012) 1238-1251.

[90] S.E. Rodgers, J.C. Demmler, R. Dsilva, R. A. Lyons, Protecting health data privacy while using residence-based environment and demographic data, Health \& Place 18(2) (2012) 209217.

[91] M. A. Barrett, T.A. Bouley, A.H. Stoertz, R.W. Stoertz, Integrating a One Health approach in education to address global health and sustainability challenges, Frontiers in Ecology and the Environment 9(4) (2011) 239-245.

\footnotetext{
i http://www.eo2heaven.org/

ii http://developer.yahoo.com/geo/placefinder/

iii http://resources.esri.com/help/9.3/arcgisserver/apis/rest/geocodeserver.html

iv http://dma.jrc.it/services/gazetteer/

ve.g., http://health2api.com/

${ }^{v i}$ The INSPIRE Directive addresses 34 spatial data themes needed for environmental applications (http://inspire.jrc.ec.europa.eu/index.cfm/pageid/2/list/7)

vii http://www.eurogeoss-broker.eu/

viii http://healthmap.org

${ }^{\text {ix }}$ http://worldwind.arc.nasa.gov/java/

${ }^{x}$ http://www.healthycity.org/

${ }^{x i}$ MedAfrica: https://www.technologyreview.com/communications/39364/?p1=A1

xii http://www.healthmap.org/outbreaksnearme
} 